\title{
SLOfit surveillance system of somatic and motor development of children and adolescents: Upgrading the Slovenian Sports Educational Chart
}

Gregor Jurak*, Bojan Leskošek, Marjeta Kovač, Maroje Sorić, Jaka Kramaršič, Vedrana Sember, Saša Đurić, Kaja Meh, Shawnda A. Morrison, Janko Strel, Gregor Starc

Laboratory of Physical and Motor Development, Faculty of Sport, University of Ljubljana, Ljubljana, Slovenia

* Corresponding author: gregor.jurak@fsp.uni-lj.si

\begin{abstract}
Slovenia is a pioneer in the systematic monitoring of physical fitness in children and adolescents. In 1969, a national system for monitoring physical and somatic development, called the Sports Educational Chart, was developed and later revised in 1987. Since 1987, all Slovenian primary and secondary schools complete three anthropometric and eight physical fitness measures to assess child development on the population level. The results are processed by the Faculty of Sport, University of Ljubljana, Laboratory of Physical and Motor Development. The Laboratory provides feedback to every schoolchild, class and school. In recent years, advanced IT support was upgraded and renamed as the SLOfit system. Registered users of SLOfit, consist of PE teachers, parents, children, and physicians, who are able to use the on-line application My SLOfit. Through My SLOfit, individuals can follow their development, assess health risks or get advice. The web platform facilitates cooperation between the educational and health system enabling a holistic approach to developmental difficulties. The My SLOfit application works as a powerful communication tool with other platforms, including a website (www.slofit.org), and Facebook. This article presents the basic features of the SLOfit surveillance system and highlights its development as a support tool for efficient, holistic data use.
\end{abstract}

KEYWORDS

physical fitness; children; physical education; population health; feedback

DOI

$10.14712 / 23366052.2020 .4$

(c) 2020 The Authors. This is an open-access article distributed under the terms of the Creative Commons Attribution License (http://creativecommons.org/licenses/by/4.0), which permits unrestricted use, distribution, and reproduction in any medium, provided the original author and source are credited. 


\section{INTRODUCTION}

Physical activity takes place in a variety of contexts, most commonly in children during play, leisure sports training, physical education at school, active transport to school, and via organized sporting activities. In the broadest sense, physical activity incorporates any movement where the muscle work represents a significant increase in energy consumption compared to rest (Caspersen, Powell, \& Christenson, 1985).

The amount and intensity of physical activity results in the improvement of physical fitness which is linked to reduced health risks and increased quality of life. Individuals with sufficient level of physical fitness can effectively carry out their daily activities without premature fatigue, and with sufficient energy. Sufficient level of physical fitness refers also to the ability to overcome an above-average physical stress of unexpected events (Clarke, 1979). Indicators of physical fitness include a full-spectrum of physical properties such as cardiovascular fitness, muscle strength, speed of movement, agility, coordination, flexibility, and can also include body composition as a physical factor. Body composition can be used as an indicator of physical fitness since it affects both work and leisure activities; it is an indicator of both health and potential health risks. In this definition, physical fitness includes morphological characteristics of an individual which influence other parameters of fitness.

Higher level of physical fitness in childhood and adolescence is associated with healthier cardiovascular and metabolic profiles and decreased risk of developing cardiovascular diseases later in life (Ruiz et al., 2009). In addition, improving physical fitness has a positive effect on mental health (Glenister, 1996) and improves the quality of life (Crews, Lochbaum, \& Landers, 2004; Dwyer, Sallis, Blizzard, Lazarus, \& Dean, 2001; Sung, Yu, So, Lam, \& Hau, 2005; Swallen, 2005). In this regard, physical fitness in childhood and adolescence can serve as an important indicator of overall health in later stages of life.

\section{What to monitor, physical activity or physical fitness?}

Assessing physical activity in regard of energy consumption above resting state remains a very challenging task despite all the technological advances in the field. Using any kind of wearable devices to assess physical activity in daily life is faced with numerous problems and the reality is that any two different devices will provide two different estimations. The problem is manifold: the definition of exercise intensity thresholds, frequency of data collection, wear time, the inability of the device to differentiate between different types of movement (e.g. cycling, walking, water activity). In addition, changes in an individual's behaviour as a response to wearing the device or various environmental factors such as weather conditions can independently affect and distort the usual behaviour we are attempting to assess. Despite these well-documented shortcomings, accelerometer-based measuring devices (i.e. objectively measured physical activity monitors) are much more reliable in assessing physical activity and energy use than subjective information obtained from activity questionnaires alone (Adamo, Prince, Tricco, Connor-Gorber, \& Tremblay, 2009).

However, even after obtaining the objectively assessed data on physical activity, there are considerable differences in energy metabolism between different individuals. Various existing recommendations on the frequency, intensity, duration and type 
of physical activity are generally ignoring these individual differences and propose universal solutions to specific needs. This means that two children involved in the same physical activity of identical duration and intensity achieve different energy consumption even if they are of the same age, sex, height and body mass. Each of them will respond differently when exposed to an identical physical activity stimulus. Due to the described limitations of physical activity as an indicator of health or developmental outcomes, we believe that measuring the direct long-term response of individual organism to physical activity - their physical fitness - provides us with more reliable indicator of habitual physical activity as well as a more stable factor in assessment of health risks. The American Heart Association has recently recommended physical fitness to be included in the vital health indicators and recorded during each doctor visit (Ross et al., 2016). Many countries are following the recommendations of several international physical health documents (i.e. health promotion activities, HEPAs) to establish systems for systematic surveillance and monitoring of physical fitness on the population level (Andersen et al., 2008; European Commission, 2014; European Council, 2013; World Health Organization, 2015). In Europe, The European Network for the Support of Development of Systems for Monitoring Physical Fitness of Children and Adolescents (FitBack) is currently developed which will provide web application for simple feedback on physical fitness testing as well as important information for stakeholders on establishing such monitoring system (FitBack, 2020).

\section{Historical and organisational outline of the Slovenian national surveillance system of physical fitness}

Slovenia can be considered a pioneer in the systematic surveillance of physical fitness of children and youth. Its first national system for surveillance of somatic and motor development in Slovenia, called the Physical Education Chart, was developed already in 1969. However, this system proved to be too ambitious for its time and was never implemented on the population level due to demanding test battery and analytical difficulties in the period when computer support was at its beginnings. It ceased to operate by the end of the 1970s but its simplified version called Sports Educational Chart version was launched in the school year 1981/82. After a six-year piloting period and a slight revision, the system was introduced to all Slovenian schools in the school year 1986/87 (Kovač, Jurak, Starc, \& Strel, 2017). Afterwards all Slovenian primary and secondary schools have been carrying out a series of physical fitness tests and anthropometric measurements every April. Every year over 200,000 children and youth aged between 6 and 19 are being measured which means that in 2019 the database included over 7.5 million sets of measurements, belonging to more than a half of the current population of Slovenia.

The test battery includes three anthropometric measurements and eight fitness tests (Table 1). The testing in schools is administered by the PE teachers who have been thoroughly trained for it during their study at the Faculty of Sport, University of Ljubljana which is the only institution in Slovenia educating PE teachers. All the schools follow the same testing protocol and use standard equipment. The results are sent to the Faculty of Sport, University of Ljubljana, Laboratory for Physical and Motor Development, where all the data is centrally analysed and within few days the feedback on the level of individual, class and school is sent back to schools. 
Table 1 SLOfit test battery

\begin{tabular}{l|c}
\hline \multicolumn{1}{c|}{ Test } & Component \\
\hline Body height & Body composition \\
\hline Body weight & Cardiorespiratory endurance \\
\hline Triceps skinfold & Muscular fitness \\
\hline 600 -meter run & Flexibility \\
\hline 60 -s sit-ups & \\
\hline Bent arm-hang & Skills related fitness \\
\hline Stand and reach & \\
\hline 20-s arm plate tapping & \\
\hline Standing long jump & \\
\hline Polygon course backwards & \\
\hline 60 -meter dash & \\
\hline
\end{tabular}

Until 1996 the participation in the Sports Educational Chart measurements was obligatory for all children and youth but in 1996 informed parental consent was introduced. The introduction of the consent, however, did not affect the participation rates which have remained over $94 \%$ in the primary school population (6- to 14-yearolds) and above $75 \%$ in the secondary school population (15- to 19-year-olds). One of the important factors, contributing to high participation rates is also the national PE curriculum which obligates teachers to survey somatic and motor development of children and youth and teach them how to monitor and influence their own developmental progress.

\section{The scope of the SLOfit surveillance system}

The scope of the SLOfit exceeds the systematic annual physical fitness testing within the educational system, which was implemented with Sports Educational Chart. It still provides direct feedback and information support to teachers, but it now operates an on-line information database of the Sports Educational Chart, which is supplemented by data obtained through questionnaires (on teenagers' physical activity and sleep habits, basic information on parents, etc.). The SLOfit reporting systems for individuals and schools now enables on-line access of parents to their children's data which is presented by rich and informative infographics. The SLOfit system is constantly evolving with upgrades so it can handle additional user information like automated input of objectively-measured daily physical activity of children collected through physical activity trackers.

According to the school legislation in Slovenia all primary and secondary schools need to follow the somatic and motor development of their children and youth and they have to offer them a choice to have their data centrally analysed and included in the national database. The exact measurement protocol is published in the Sports Educational Card manual (Kovač, Jurak, Starc, Leskošek, \& Strel, 2011), which is 
a compulsory tool for every PE teacher and is freely available at the SLOfit web site (www.slofit.org/ucitelj/administracija).

An important scope of the SLOfit system is to enable individuals to use their data for exercise planning and monitoring so they can improve or maintain their physical fitness throughout their lifespan. With this the SLOfit system encourages them to optimise the quality and quantity of their habitual physical activity. Given the limited possibilities of communication between schools, physicians, municipalities, and parents it is increasingly important to establish this communication and continue improving the conditions for children's healthy development on both, individual and population level, in their homes and in schools. The SLOfit group is directly developing the system which ensures effective and efficient diagnosing of health risks in children, and suggest the most useful interventions with helpful feedback focusing on the key end-users, including PE teachers, parents, children and school physicians (Jurak et al., 2017). From school year 2017/18 the registered users are already able to access information support through the SLOfit website (www.slofit.org) and a free web application My SLOfit (moj.slofit.org).

With professional support, members of the SLOfit groups can experience a kind of connectivity that enables the introduction of innovative models, contacts, and implementation of early interventions to reduce obesity, or identify deficits in a particular area of somatic or motor development. One of the aims of the SLOfit work group is to have SLOfit data of both children and their parents who participated in the programme some 30 years ago accessible to them. This would allow parents to directly compare their childhood somatic and motor development to the development of their children, and would enable researchers to develop more advanced predictive models that could effectively help the identification of children with increased developmental

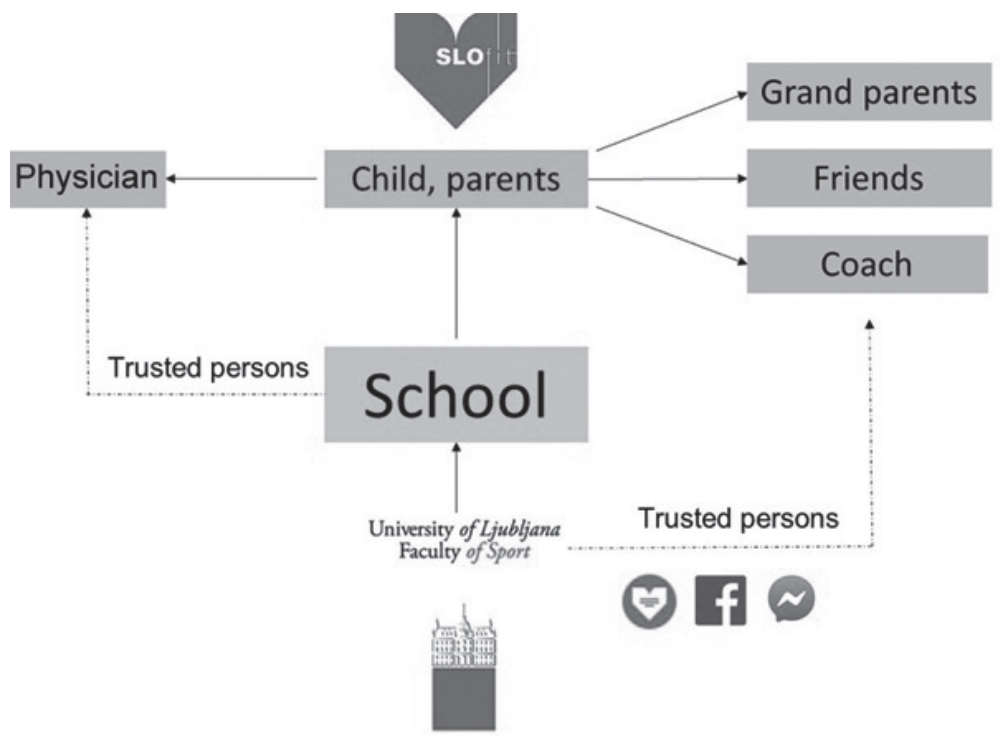

Figure 1 SLOfit user relationships 
and health risks and the planning and implementation of interventions. In this way the application will provide lifelong monitoring of physical fitness to individuals and families as a whole.

My SLOfit is constructed as a vital diagnostic and surveillance tool for use in schools (Figure 1). All data use is regulated in accordance with GDPR. Schools are using the system free of charge on the basis of the SLOfit service agreement and appoint a school administrator who is responsible for the communication between the SLOfit team and the school. Every school administrator is responsible for managing all the users in one's school. They are the ones acquiring parental consents, importing the lists of children and parental e-mail addresses, inputting the results of measurements, verifying the submitted school data and communicating the feedback to the school principal, to other teachers, parents and municipalities. All school administrators are required to attend a free of charge training at the Faculty of Sport which is the prerequisite for the schools to start using the My SLOfit application.

It is the school administrator who grants access to children's data to other teachers from the school, while the school can also decide to propose to parents to grant access to children's data to the school physician. However, it is the parents who need to confirm this access and as a result, the school physician is invited to register and become a user. Data are not shared with anyone without positive consent of parents or students already of age (18 years or above). They also have an option to invite any other person to look at their children's data and are the ones who control the data access. The consent to look into individual child's data can be revoked at any time with a few clicks.

Every school year the school administrators import the list of children, currently enrolled in their schools in the My SLOfit aplication. They can update the list at any time and simultaneously also import the parental data and e-mail addresses of the parents who gave their consent. After the children's data for a certain school year is gathered and inputted in schools, and later checked, analysed and confirmed at the Faculty of Sport, the parents and receive the invitation to either register in My SLOfit if they are the first-time users, or receive a notification that the latest data of their children is now available if they had already been registered before. Finally, parents or students of age 18 can revoke their consent for their personal data to be included in SLOfit at any time by submitting a request within the My SLOfit application. In such case, personal information in SLOfit will be anonymised no later than 15 days after the cancellation request is received.

Parents or students always access their personal and children's personal information with username and password to. They have the right to change their personal data, add new data or change the data they had put in before but they cannot change the physical fitness data that was inputted by the school. All the data in the SLOfit database is automatically anonymised one year after an individual finishes one's education. All the users are notified before anonymisation and are given an option to permanently store and access the data in the application. Anonymised SLOfit data are afterwards used for statistical and scientific research in accordance with the agreement of the Commission on Ethical Issues in Sport No. 6-2019-539. 


\section{Diagnostics of physical fitness in SLOfit}

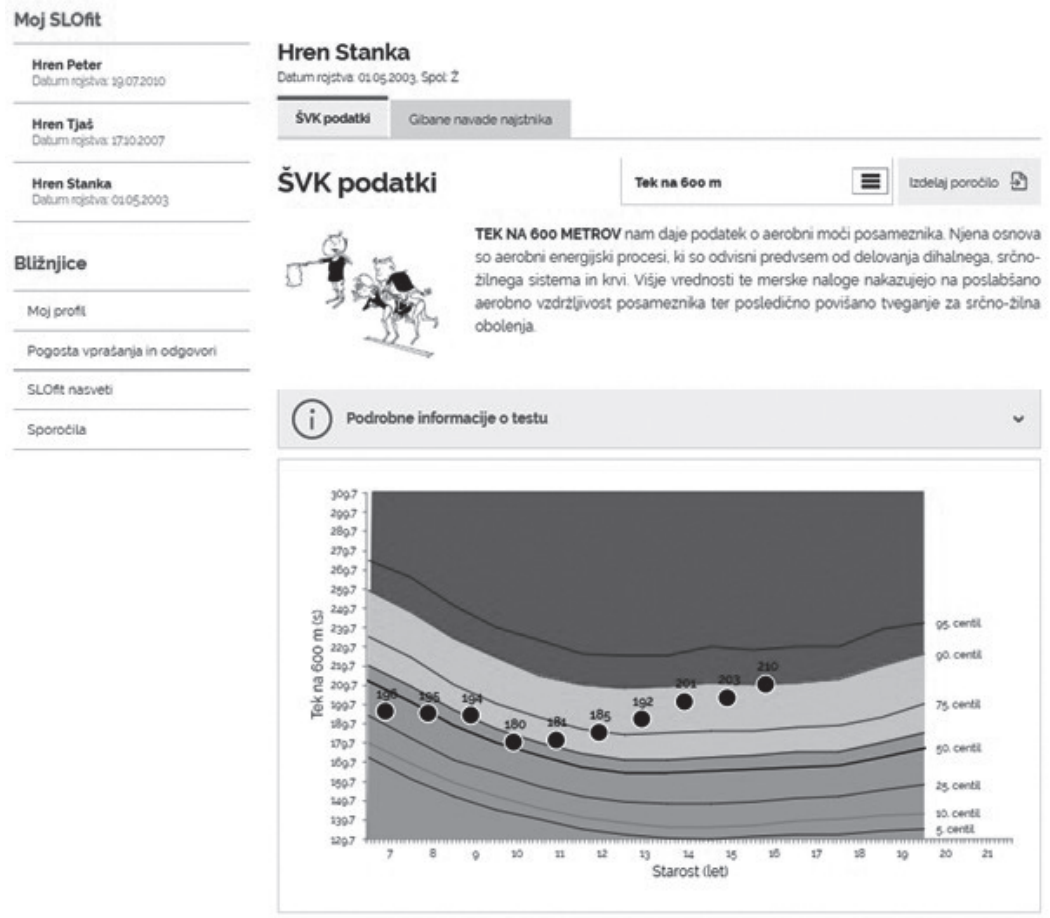

Figure 2 Parental view in the My SLOfit application - longitudinal development of one of the fitness components

The My SLOfit application provides schools and individuals with administrative and analytical support in collecting, storing and displaying the data. It is customized for use on different screen sizes (PCs, laptops, smartphones, tablets). Users can access their results and receive feedback (Jurak et al., 2017), for example: the change rate in one year, the trends of their somatic and motor development throughout the years of their schooling, comparison of their scores with the population (expressed in percentile value), and in which group of physical performance or health risk individual results are classified. If a parent has more than one child the information for all children can be accessed within one's user account (Figure 2).

The triceps skinfold, BMI and fitness data in the My SLOfit application are presented according to health risks, based on the existing scientific evidence (Laurson, Eisenmann, \& Welk, 2011; Morrow \& Zhu, 2008; Starc et al., 2016; Welk, Going, Morrow, \& Meredith, 2011). Health risks are increased when subcutaneous fat and/or BMI are high or very low. On the other hand, the results of fitness tests have a one-way risk direction - the better the result, the smaller the risk. General direction of the individual test depends on its characteristics. In some cases, a lower absolute and percentile value is more beneficial to health outcomes (e.g. 600 meter run is expressed as time meaning 
the shorter time the faster run), whereas in other tasks, the opposite is true (e.g. bentarm hang time is also expressed as time but the longer the time the better the result).

The presentation of physical fitness results and their corresponding motor abilities and physical characteristics also points out the trends of development and highlights the areas where elevated risk is emerging. Parents can contribute to information on their own (described below), and they can also obtain additional information from the child's teacher. PE teachers are trained in the correct interpretation of the physical fitness data and use this data to plan, implement and monitor the effectiveness of their work.

Improving cooperation and enabling communication between the school, parents and healthcare system is an important added value of the SLOfit system that helps in reducing health risks for children and adolescents who may be overweight, physically inactive or have low physical performance. This cooperation was traditionally limited only to the regular, systematic health checks but with a possibility of school physicians to access individual child's data, this data becomes a part of an on-going surveillance which helps in identification of at-risk children.

By looking at the data of an individual child, a physician can obtain information on the longitudinal somatic and motor development of a child and can compare it with other data collected in the SLOfit (Figure 5). These data enable physicians to get a better insight into children's development as a basis for writing recommendations for individualisation in PE class, or inclusion in any other intervention program. Kinesiologists, as members of the healthcare team, can construct individual exercise programs in collaboration with the PE teacher for every child with diagnosed increased risks. In the case of inclusion of a child in the treatment and in the programs managed by the health system, this information also enables the physicians to monitor the effects of the treatment or the intervention. Algorithms of cooperation between the health and school teams, and diagnostics for physicians using My SLOfit are constructed and the treatment is conducted to improve exercise capacity and nutritional status of children (Truden-Dobrin et al., 2019).

\section{Individual SLOfit report}

There are currently three levels of feedback available to every individual user of the My SLOfit application: 1. longitudinal development of physical fitness for all years of schooling (in HTML format; Figure 2), 2. the current status of physical fitness (in PDF format; Figures 3 and 4) and 3. physical activity and sleep habits (in the PDF format; Figure 5).

Results for children and adolescents are evaluated according to health benefits/ risks and give information about the position of an individual within the population of one's peers (of same age and sex). The different health risk areas are marked with different colours: green $=$ healthy zone, yellow $=$ low risk - recommended improvement, red = increased risk - necessary improvements. Reports also provide explanations to enable users to better understand the classification.

The on-line reports in My SLOfit have links that lead the child or adolescent and his parents to tips for improving individual components of physical fitness and other important information related to physical fitness and physical development of the child. Within the application My SLOfit parents can directly communicate with teachers 


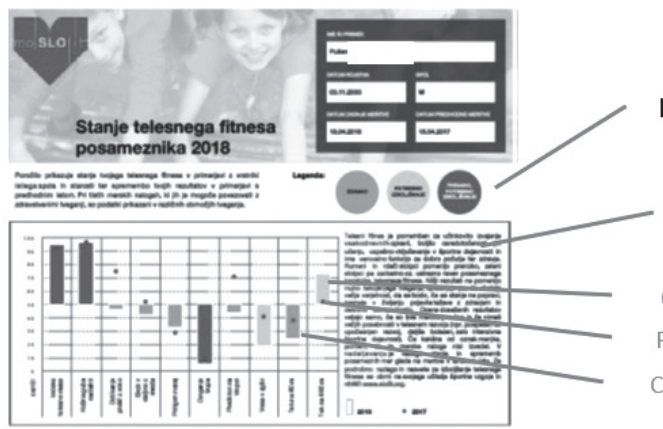

Health-risk zones description

Profile of current PF compared to previous measurements with short instructions for reading

\section{Current year}

Previous year

Color regards to health-risk zone

Figure 3 Excerpt from the individual report on the current of physical fitness status - personal physical fitness profile

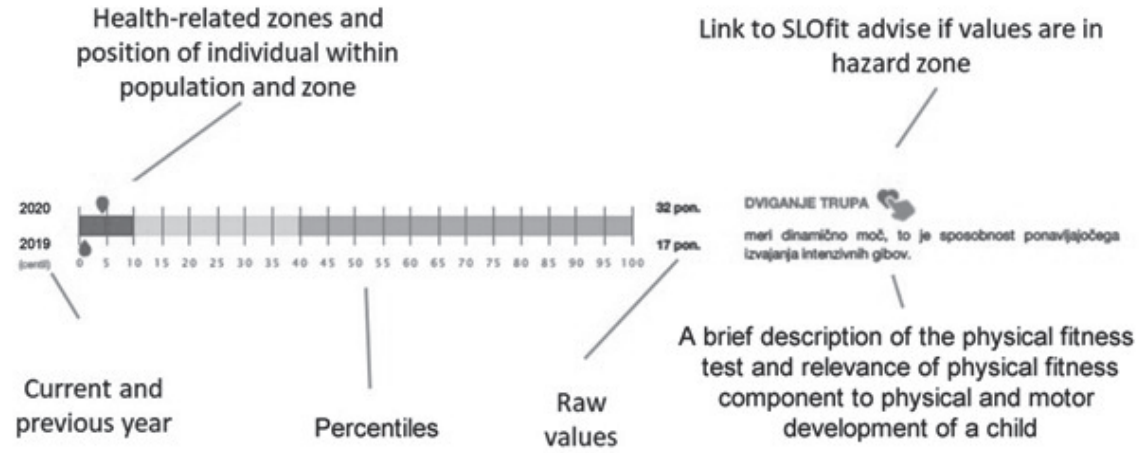

Figure $4 \mathrm{~A}$ detail from the individual report on the current physical fitness status - results of individual test


E- =-1-- Fehaviour with recommendations and links to SLOfit advise

Figure 5 SLOfit report on physical activity and sleep habits 
while teachers can involve the SLOfit team from Faculty of Sport into this communication when a higher level of expertise is required. Otherwise, parents can also follow the professionally-moderated SLOfit Facebook profile page with up-to date information on different aspects of physical activity, physical fitness and healthy lifestyles.

Additionally, the SLOfit system enables users (parents or adolescents) to complete a report on weekly physical activity. This includes a daily account of moderate and vigorous physical activity, screen-time and sleep habits. After the completion of the questionnaire, the users can generate a report with the health risk assessment and compliance with the existing recommendations and links to advices.

\section{School SLOfit report}

Within the school administrator's profile, schools can access the School SLOfit report which has three levels: 1 . the current status of physical fitness of each class (Figure 6), 2. physical fitness profile of each class with the share of at-risk children (Figure 6), and 3. the current status of physical fitness of the entire school and longitudinal trends of different components of physical fitness (Figure 7).

The class-level of school report enables teachers to diagnose the physical fitness status of an individual child or entire class, which enables appropriate individualization or differentiation of the learning process within the regular PE classes.

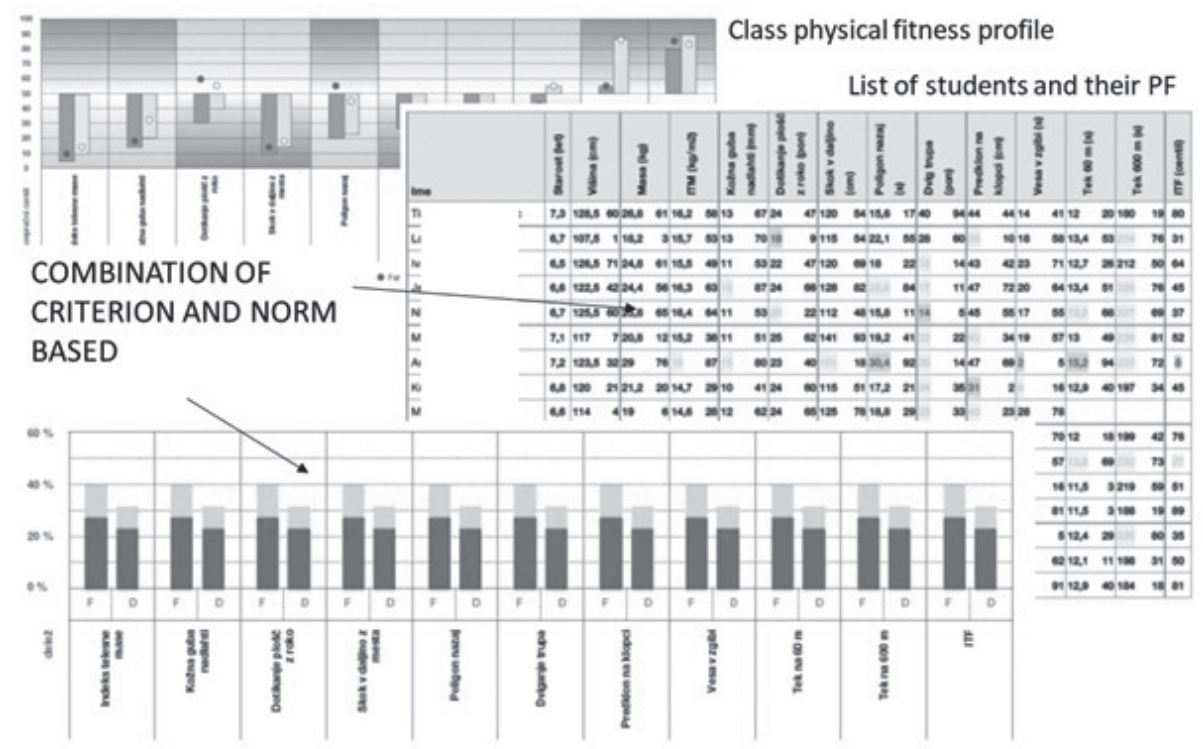

Share of unfit, health-risk children

Figure 6 Some excerpts from the class-level of school report 


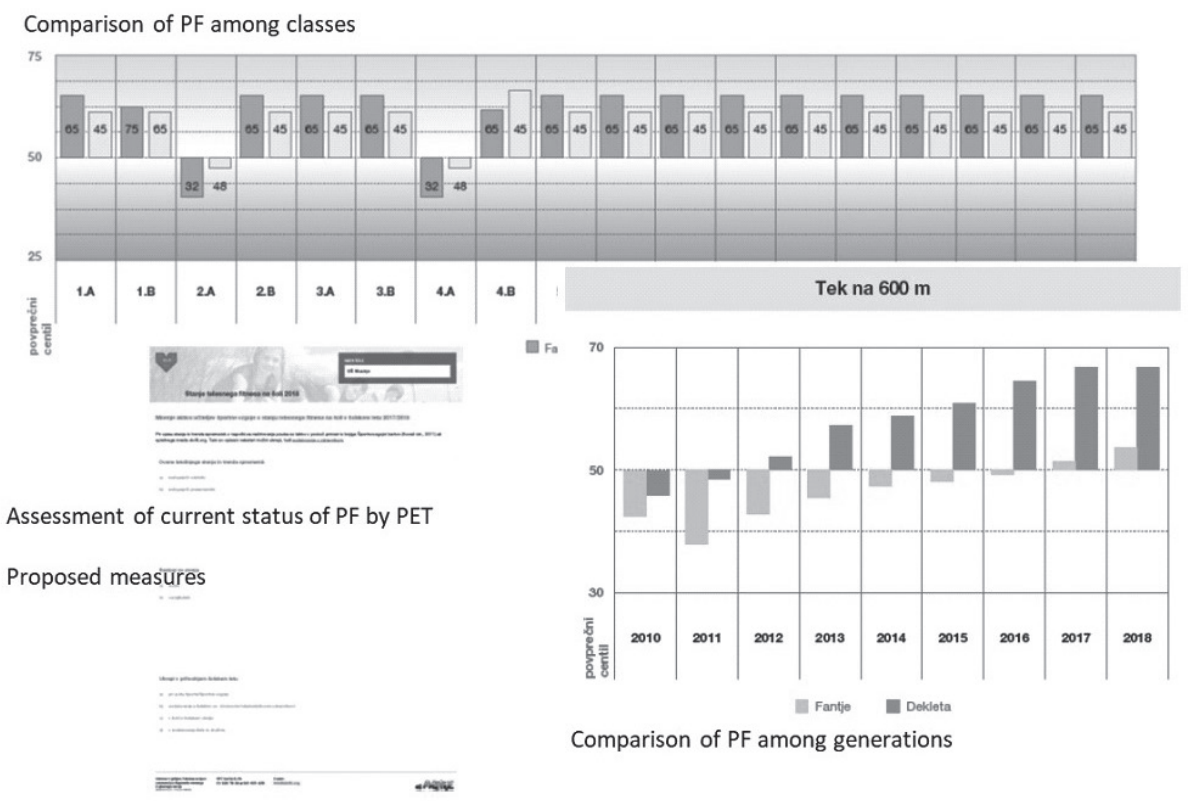

Figure 7 Some excerpts from the school SLofit report - current status of physical fitness of the entire school

The school report allows PE teachers to analyse in detail the status of physical fitness in and between classes, and between generations of children, by gender and by individual physical fitness components. The reporting system is designed in such a way that PE teachers can supplement the report with the specifics they have identified during the school year and are important for interpreting and understanding the results and for improving the situation. On this basis, PE teacher may propose new measures for the coming school year to the school management. The report thus provides a good overall picture of the status of physical fitness for a given group of pupils, as well as straightforward identification of children at risk in a given class and across the school. In this sense it provides an excellent basis for planning regular PE classes as well as other activities of the extra-curriculum (supplementary PE classes, physically active morning care, school sport activities, physically active recesses, etc.) with the aim of improving physical fitness with more physical activity within school setting (Jurak et al., 2016; Poličnik et al., 2016; Strel, Jurak, Starc, \& Strel, 2016).

\section{Looking forward}

Along with its existing features, the information infrastructure of the SLOfit system offers a variety of upgrade options. The SLOfit team has already designed a system for lifelong physical fitness surveillance using the SLOfit system, which will allow individuals to check and evaluate their physical fitness well into adulthood. Another possible upgrade of the SLOfit system is the acquisition of physical activity data from smart wristbands and their inclusion in the individual SLOfit report. This will enable a unique follow-up possibility to physical activity interventions. Currently the SLOfit 
team is constructing predictive models of somatic and motor development which will enable researchers to estimate future trends in fitness changes and thus evaluate the effects of different interventions on a population in a near-real time. The SLOfit team is closely following the development of artificial intelligence technology that could allow the collection and analysis of large amounts of data on individual's movement habits (e.g., physical activity data from wristbands, movement through geographical location, use of public transport, ), which could further improve the predictive models and enhance people's lifelong physical fitness. The SLOfit system is guided by the goal to promote physically-literate and non-sedentary lifestyle behaviour patterns in Slovenian society, supported by high-quality data.

\section{REFERENCES}

Adamo, K. B., Prince, S. A., Tricco, A. C., Connor-Gorber, S., \& Tremblay, M. (2009). A comparison of indirect versus direct measures for assessing physical activity in the pediatric population: a systematic review. International Journal of Pediatric Obesity, 4(1), 2-27.

Andersen, L. B., Anderssen, S., Bachl, N., Banzer, W., Brage, S., Brettschneider, W.-D., ... Vass, H. (2008). EU Physical Activity Guidlines Recommended Policy Actions in Support of Health-Enhancing Physical Activity, 1-38.

Caspersen, C. J., Powell, K. E., \& Christenson, G. M. (1985). Physical activity, exercise, and physical fitness: definitions and distinctions for health-related research. Public Health Reports, $100(2), 126$.

Clarke, H. H. (1979). Academy approves physical fitness definition. Physical Fitness Newsletter, 25(9), 1.

Crews, D. J., Lochbaum, M. R., \& Landers, D. M. (2004). Aerobic Physical Activity Effects on Psychological Well-Being in Low-Income Hispanic Children. Perceptual and Motor Skills, 98(1), 319-324.

Dwyer, T., Sallis, J. F., Blizzard, L., Lazarus, R., \& Dean, K. (2001). Relation of academic performance to physical activity and fitness in children. Pediatric Exercise Science, 13(3), $225-237$.

European Commission (2014). EU Action Plan on Childhood Obesity 2014-2020. A growing health challenge for the EU. Comisión Europea ( July 2014), 68.

European Council (2013). Council Recommendation of 26 November 2013 on promoting health-enhancing physical activity across sectors. Official Journal of the European Union, Brussels (4 December), 1-5.

FitBack - The European Network for Support of Physical Fitness Monitoring Systems (2020). University of Ljubljana, Faculty of Sport. Retrieved from https://www.fsp.uni-lj.si/en /research/projects/international-projects/eu-projects/2019111110541878.

Glenister, D. (1996). Exercise and mental health: A review. The Journal of the Royal Society for the Promotion of Health, 116(1), 7-13.

Jurak, G., Leskošek, B., Kovač, M., Sorić, M., Sember, V., Strel, J., \& Starc, G. (2017). Kako naprej s SLOfit-om? [How to go further with SLOfit?]. Šport, 55(3-4), 208-214.

Jurak, G., Starc, G., Kovač, M., Kostanjevec, S., Radi, P., Erjavšek, M., ... Krpač, F. (2016). Priročnik za preventivne time za izpeljavo dejavnosti na področju gibanja in prehrane $v$ pilotnem testiranju projekta Uživajmo $v$ zdravju [A guide for preventative teams to derive motoric and nutrition activities in pilot project testing Let enjoy in health]. In: Jurak, G. (Ed.). Ljubljana: Univerza v Ljubljani.

Kovač, M., Jurak, G., Starc, G., \& Strel, J. (2017). SLOfit ali športnovzgojni karton skozi zgodovinsko perspektivo SLOfit [SLOfit or sports card through the historical perspective of SLOfit]. Šport, 65(3/4), 152-166. 
Kovač, M., Jurak, G., Starc, G., Leskošek, B., \& Strel, J. (2011). Športnovzgojni karton: diagnostika in ovrednotenje telesnega in gibalnega razvoja otrok in mladine $v$ Sloveniji [Sports card: diagnostics and evaluation of physical movement development of children and youth in Slovenia]. Ljubljana: Fakulteta za šport.

Laurson, K. R., Eisenmann, J. C., \& Welk, G. J. (2011). Development of youth percent body fat standards using receiver operating characteristic curves. American Journal of Preventive Medicine, 41(4), S93-S99.

Morrow, J. R., \& Zhu, W. (2008). Physical fitness standards for children. Fitnessgram ${ }^{*}$ Activitygram $^{\circ}$ Reference Guide. Dallas, TX: The Cooper Institute, 70-83.

Poličnik, R., Berlic, N., Zakotnik, J. M., Kostanjevec, S., Starc, G., Jurak, G., \& Smajlović, S. K. (2016). Algoritem delovanja različnih deležnikov v lokalnih preventivnih timih po konceptu skupnostnega pristopa: navodila preventivnim timom za sodelovanje v pilotnem testiranju [Algorithm of action of different stakeholders in local prevention teams following the concept of community approach: instructions to prevention teams to participate in pilot testing]. Nacionalni inštitut za javno zdravje.

Ross, R., Blair, S. N., Arena, R., Church, T. S., Després, J. P., Franklin, B. A., ... Wisløff, U. (2016). Importance of Assessing Cardiorespiratory Fitness in Clinical Practice: A Case for Fitness as a Clinical Vital Sign: A Scientific Statement from the American Heart Association. Circulation, 134(24), 653-699.

Ruiz, J. R., Castro-Piñero, J., Artero, E. G., Ortega, F. B., Sjöström, M., Suni, J., \& Castillo, M. J. (2009). Predictive validity of health-related fitness in youth: A systematic review. British Journal of Sports Medicine, 43(12), 909-923.

Starc, G., Strel, J., Kovač, M., Leskošek, B., Sorić, M., \& Jurak, G. (2016). Telesni in gibalni razvoj otrokv Sloveniji : šolsko leto 2015/2016 [Physical and motoric development of children in Slovenia]. Ljubljana: Laboratorij za diagnostiko telesnega in gibalnega razvoja, Fakulteta za šport.

Strel, J., Jurak, G., Starc, G., \& Strel, J. (2016). Telesna zmogljivost za bolǰ̌e zdravje in počutje : vloga osnovnega zdravstva in lokalne skupnosti pri zagotavljanju ustrezne telesne zmogljivosti po vrhniškem modelu [Physical fitness for better health and well-being: The role of primary health care and the local community in providing adequate physical fitness according to a peer model]. In: Strel, J., Mišič, G., Strel, J., \& Glažar, T. (Eds.), Telesni fitnes $v$ funkciji zdravja. Logatec: Fitlab.

Sung, R. Y. T., Yu, C. W., So, R. C. H., Lam, P. K. W., \& Hau, K. T. (2005). Self-perception of physical competences in preadolescent overweight Chinese children. European Journal of Clinical Nutrition, 59(1), 101-106.

Swallen, K. C. (2005). Overweight, Obesity, and Health-Related Quality of Life Among Adolescents: The National Longitudinal Study of Adolescent Health. Pediatrics, 115(2), 340-347.

Truden-Dobrin, P., Jurak, G., Kotnik, P., Klemenčič, S., Benedik, E., Vogrin, B., ... Dravec, S. (2019). Družinska obravnava za izboljšanje telesne zmogljivosti in prehranjenosti otrok [Family treatment to improve physical fitness and children nourishment]. Ljubljana: Nacionalni inštitut za javno zdravje.

Welk, G. J., Going, S. B., Morrow, J. R., \& Meredith, M. D. (2011). Development of new criterion-referenced fitness standards in the FITNESSGRAM ${ }^{\circ}$ program: rationale and conceptual overview. American Journal of Preventive Medicine, 41(4), S63-S67.

World Health Organization (2015). Physical activity strategy for the WHO European Region 2016-2025. World Health Organization (September 2015), 32. 